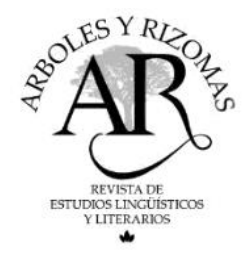

Árboles y Rizomas Vol. III, No 2 (Julio-Diciembre, 2021): 36-52

Universidad de Santiago de Chile, ISSN 0719-9805

https://doi.org/ 10.35588/ayr.v3i2.5001

\title{
El lugar de la naturaleza en el espacio poético: identidad, pertenencia y experiencia
}

\section{The place of nature in poetic space: identity, belonging and experience}

\author{
Julieth Niño ${ }^{2}$
}

Resumen

Este artículo tiene como propósito explicar la articulación de la crisis ambiental en los textos líricos por medio de un análisis de los conceptos de naturaleza y territorialidad. Partimos de la siguiente premisa: los problemas de territorialización aparecen como herramienta de análisis en la poesía, ya que permiten comprender el territorio como un lugar en disputa donde se desatan grandes conflictos ecológicos, por lo tanto, la escritura logra recuperar el lugar dentro de un diálogo viviente entre el pasado, el presente y el futuro, lo que significa un esfuerzo por volver a habitar estos territorios. En este sentido, la presente investigación despliega un estudio de la escritura lírica de origen mapuche a partir de las articulaciones políticas, sociales, culturales y ambientales provenientes de los estudios literarios.

Palabras claves: naturaleza, mapuche, poesía, territorio, crisis ambiental.

\begin{abstract}
The purpose of this article is to explain the articulation of the environmental crisis in lyrical texts through the analysis of the concepts of nature and territoriality. We start from the following premise: the problems of territorialization appear as a tool of analysis in poetry, since they allow us to comprehend the territory as a place in dispute where great ecological conflicts are unleashed. Therefore, the writing manages to recover the place within a living dialogue between the past, the present and the future, which means an effort to re-habit these territories. In this sense, this study focuses on the lyrical writings of Mapuche origin based on the political, social, cultural, and environmental articulations derived from literary studies.
\end{abstract}

Keywords: nature, Mapuche, poetry, territory, environmental crisis.

\footnotetext{
${ }^{1}$ El presente artículo hace parte del proyecto FONDECYT regular N ${ }^{\circ} 1180001$ "Tortura: Concepto y Experiencia".

${ }^{2}$ Estudiante de Doctorado en Estudios Americanos USACh - IDEA. Correo: juliethn1015@gmail.com. ORCID ID: https://orcid.org/0000-0003-2735-0337
}

Recibido: 01.07.2021

Aceptado: 05.10.2021 
El lugar de la naturaleza en el espacio poético: identidad, pertenencia y experiencia

Julieth Niño

\section{Introducción.}

Nuestra investigación tiene como objetivo proponer y explicar cómo se articula el concepto de naturaleza y territorio en la escritura lírica. Para Mora (2013), el lugar o el territorio se manifiesta como una estrategia compleja de identidades culturales donde se revelan los problemas de la modernidad. La recuperación del lugar como territorio cultural desde la lírica resulta fundamental para los efectos de movilización social. En este sentido, la escritura que trabajaremos a continuación abre espacios discursivos a debates fundamentales sobre la territorialización y la desterritorialización, inscritos a partir de varios discursos como el de la memoria, el discurso testimonial y los discursos ambientales, que logran posicionar estas poéticas desde el activismo social (praxis).

El ejercicio de la escritura nos lleva, como lectores, a proponer la poesía como un lugar de identidad donde el territorio aparece como eje central de los textos líricos seleccionados. Observemos las palabras de la mapuche Graciela Huinao: “Acá en Santiago fue otro mundo, no sabía dónde estaba el Norte ni el Sur, la única alegría que tenía era cuando la luna alumbraba la casa donde yo trabajaba como nana y pensaba que era la misma luna que iluminaba mi hogar en el Sur" (en Morales, 2002, p. 5). El territorio abarca aquí un sentido amplio de su significado que va a ser interpretado bajo el análisis semántico de la palabra. Estas líricas permiten situar al lector/a en un espacio en común donde la escritura no sólo transcribe narraciones testimoniales de hechos reales, sino que también (re)construye la espacialidad de los lugares, a través de los datos históricos que nos proporciona una (re)ubicación geográfica de los paisajes. Esta investigación partirá de dos aproximaciones: por una parte, entenderemos la escritura de estos textos como herramienta semántica en la que la naturaleza se transforma en eje articulador dentro de las obras, por otra parte, tomaremos estas escrituras como un micro-acto que funciona como una práctica que permite volver a dibujar los territorios en disputa.

\section{Naturaleza y territorialización}

Antes de la llegada del hombre europeo, la naturaleza se consideraba como un gran organismo cósmico en que los pueblos originarios de América eran parte integral e inseparable del ecosistema ${ }^{3}$. En este sentido, más que un inicial enfrentamiento entre "civilización y barbarie" según la fórmula de Sarmiento (1845), lo que hubo fue un choque de cosmovisiones radicales: por un lado, el antropocentrismo anti-natural de Occidente y, por el otro, el geocentrismo vitalista de

\footnotetext{
${ }^{3}$ Hacemos referencia de los procesos colonizadores desatados con el descubrimiento de América el 12 de octubre del 1492. Como lo afirma Quijano, el descubrimiento y conquista de América fue la más ambiciosa empresa colonial en la historia de la humanidad y del capitalismo, al conjugar las formas de dominación y subordinación para mantener y justificar el control sobre los territorios en las Américas (1988).
} 
El lugar de la naturaleza en el espacio poético: identidad, pertenencia y experiencia

Julieth Niño

los indígenas ${ }^{4}$. La conquista significó una lucha por vencer no sólo lo indígena, sino también el ecosistema que lo sostenía, convirtiendo así a la naturaleza en un territorio colonizado. Siguiendo a Binns (2004), la conquista de América en las últimas décadas se ha empezado a leer desde una perspectiva ecológica, pues los bosques han sido desde comienzos de la historia de la colonización un obstáculo para dicha empresa. Según lo señala el autor:

El bosque desaparece también, en tierras colonizadas por el imperio de turno, porque constituye una amenaza, un depositario de valores y relatos fundacionales del lugar que la potencia colonizadora necesita anular para mejor dominar: pues los bosques eran obstáculos para la conquista, la hegemonía y la homogenización. Eran, en una palabra, asilo de independencia cultural. (p. 10)

Los alcances del estudio sobre el territorio son tan amplios como los alcances de los estudios culturales. La naturaleza, como lugar de tradición, parece ser un punto de partida donde se logra constituir la base de la existencia individual y colectiva de una comunidad. De allí la importancia de ver cómo se desarrollan estos puntos de inflexión en donde se cruzan la construcción de la memoria, la cultura, la sociedad y las (re)construcciones cartográficas como representación de los territorios descolonizados. Para Hall (1996), la representación es una consecuencia de identidades que se relaciona tanto con la invención de la tradición como la tradición misma, lo que permite leer estas representaciones como una narrativa en constante cambio. La escritura, en este sentido, se convierte en un elemento simbólico en continuo movimiento que (re)constituye los imaginarios del lugar. Entenderemos estas poéticas como mecanismos de representaciones modulares que se encuentran inmersas en el contexto social y la geografía espacial de los territorios en disputa. Zambrano (2008) afirma que "representar en un sentido general es volver al presente, repetir la presencia colocar una cosa en lugar de otra" (p.227). El (re)mapear los territorios se ha convertido en una representación del texto, pues la construcción cartográfica revitaliza los conocimientos ancestrales, (re)significa los paisajes y legitima la experiencia y la identidad de las comunidades. Es en este sentido, la escritura se convierte en un micro-acto porque logra la participación entre el texto, el lector y el contexto desde donde se levantan estas poéticas.

El levantamiento cartográfico ha sido desde la colonización una estrategia para controlar los territorios, los recursos naturales y a las personas que habitan estos espacios. El estudio sobre el territorio da cuenta de las tradiciones, de las organizaciones sociales y de las dimensiones geográficas, religiosas y políticas que se cimientan en esas tierras. Lo que hace tan importante la noción de territorialización en América Latina, como lo afirma Offen (2009), es que este fenómeno

\footnotetext{
${ }^{4}$ Sarmiento (1845), llama “civilización y barbarie" al enfrentamiento político y social entre las fuerzas unitarias y las federales, representadas estas últimas por los gauchos y sus caudillos, que tuvo lugar durante las guerras civiles argentinas del siglo XIX.
} 
El lugar de la naturaleza en el espacio poético: identidad, pertenencia y experiencia

Julieth Niño

representa los procesos a través de los cuales se interviene en pro de los derechos territoriales y culturales.

Los lugares y los sentidos de lugar, así como las redes sociales tejidas a través de ellos no se pueden separar de los procesos políticos que buscan su territorialización. Los proyectos participativos de mapeo, por supuesto, no son la excepción. Las prácticas de reproducción de la vida material, los dichos populares en torno al lugar, y las cadencias culturales enraizadas en el paisaje natural son mediaciones de cualquier noción de territorio, y por lo tanto están entretejidas con las estrategias políticas que buscan el reconocimiento de los lugares. (p. 170)

Los proyectos de mapeo buscan el reconocimiento del territorio ancestral bajo la noción de propiedad y autonomía donde circulan un sin número de tradiciones que se encuentran fuertemente vinculadas con la naturaleza. El medio ambiente hace parte de las luchas por la recuperación de los lugares. En tal sentido, el mapeo identifica principalmente las zonas de minerales, ríos y glaciales para su protección. Siguiendo el mapeo que realizó la comunidad mapuche en la Región de los Ríos, límites con Argentina, en el 2017, se identifica aquí las zonas de asentamiento indígenas, los terrenos de producción agrícola, los ríos y valles que transitan en este territorio. En este sentido, la tierra no es solamente el lugar donde habita una comunidad, sino el espacio territorial donde fluye la existencia de la vida humana y natural. Observemos la siguiente cartografía en la Figura 1.

Figura 1: Ilustración de: Pablo Marimán, historiador Mapuche (2018)

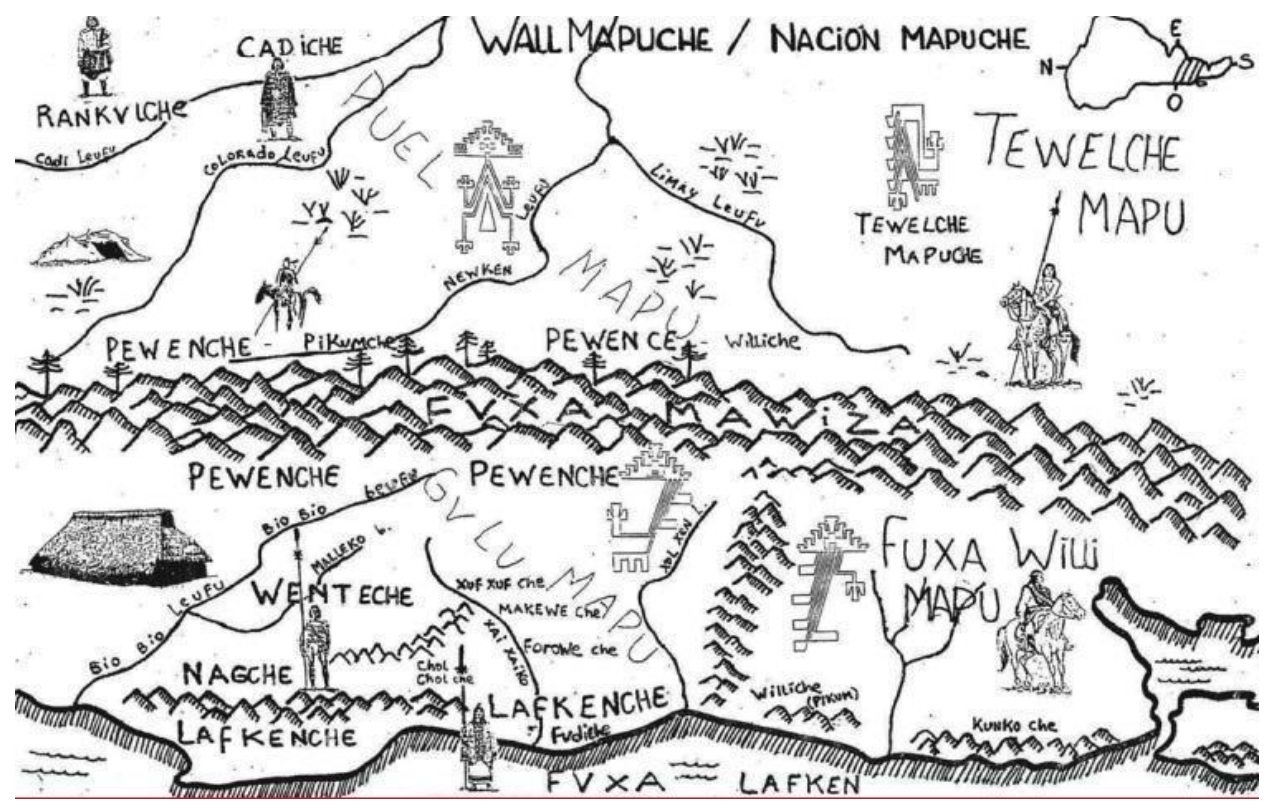

Fuente: https://www.mapuexpress.org/ 
El lugar de la naturaleza en el espacio poético: identidad, pertenencia y experiencia

Julieth Niño

El mapeo anterior, tiene la intención de denunciar el daño ambiental que por décadas ha sufrido la Wallmapu, pero también se toma como un ejercicio o recurso de la memoria, porque su construcción se fundamenta en las cosmovisiones de las comunidades indígenas que habitan estos espacios. Es así que esta cartografía representa un acto social y político de arraigo cultural que busca la decolonización o la descentralización del poder Occidental (invasores) en su territorio.

Los mapas han sido una herramienta decolonizadora en los últimos años en Latinoamérica. Las cartografías son ilustradas con el objetivo de mostrar las leyendas, las tradiciones, las historias y deconstruir el pensamiento colonizador. Es así como "los mapas indígenas son diseñados para ilustrar la ocupación y mostrar su relación con la tierra" (Offen, 2009, p. 160). En el Manifiesto decolonial que realiza el argentino Mignolo se devela la propuesta de construir una "teoría crítica" latinoamericana que desplace la teoría decolonial del siglo XX que hasta el momento seguía nombrando a América como un territorio en disputa. El giro decolonial debe incorporar temas como territorio, clase, género, geografía y naturaleza. Siguiendo a Mignolo (2007) "se hace urgente un pensamiento decolonial para desprendernos de la racionalidad moderna" (p.17).

Lo decolonial aparece desde este punto de vista como un escenario social y político, que hace visibles y objetivas las nuevas formas de subordinación y dominación, lo que resulta central para comprender las prácticas colonizadoras sobre los territorios conquistados. Por lo tanto, ya no se tratará de conocer la "verdadera" historia de las Américas, sino de reconocer los lugares que constituyen la memoria colonial, las huellas desde donde se teje el pensamiento decolonial. Sostenemos que la poesía logra desprender las lógicas modernas y sitúa al yo lírico como un discurso literario que retorna nuevamente a su relación con el entorno habitado; otorgándole así un inevitable sentido social, en el que el lector/a siente, mira y representa el mundo a través del poema. Para Escobar (2000), el lugar es un elemento esencial para la construcción de la realidad.

La relación entre los significados y las prácticas -y las relaciones sociales en las que están arraigadas- está siendo transformada hoy por la acometida del desarrollismo que conlleva la pérdida de conocimiento y territorio, además de convertir la naturaleza en una mercancía. La demarcación de los territorios colectivos por parte de los Estados ha llevado a los habitantes originarios a desarrollar una concepción nueva del territorio que resalte las articulaciones entre los patrones de asentamiento, uso de los espacios, y prácticas del conjunto del significado-uso de los recursos. (p.78)

Desde esta perspectiva, volver a demarcar los territorios se propone como una lucha contra hegemónica donde se (re)significan las experiencias con los lugares; la poesía trabaja en esta resignificación a través de la narración testimonial, biográfica e histórica que se vincula con la experiencia de habitar lugares aparentemente olvidados. La voz lírica permite la recuperación de la memoria histórica y el levantamiento geográfico de nuevas territorialidades, lo que posibilita la creación de discursos que apuntan a una identidad desde la pluralidad y la diversidad, que, a su vez, abordan problemáticas como tradición, mestizaje y naturaleza. En el siguiente poema escrito 
El lugar de la naturaleza en el espacio poético: identidad, pertenencia y experiencia

Julieth Niño

por la mapuche María Isabel Lara Millapan (2006), logramos identificar un encuentro personal con la tradición que se conjuga con la expresión del mundo natural que circula a su alrededor.

\author{
ADKINTUN \\ Llevo mi voz al viento \\ Y en la llovizna transparente \\ Ruego a mis antepasados, \\ Busco tu espíritu \\ Que hable de la sabiduría de la tierra \\ Que entone el canto \\ De las aves del sol \\ Que comprenda el silencio de los sueños \\ La visión de las aguas \\ Y el secreto de los árboles antiguos \\ Para tejer el telar \\ De nuestro rostro mapuche. (p. 45)
}

El título del poema escrito en Mapudungun nos instala como lectores en un lugar concreto donde lo ancestral se posiciona como protagonista, la voz de la escritora se une en un encuentro íntimo con la naturaleza donde recorre un camino lleno de árboles frondosos que guarda el secreto de la existencia mapuche, las aves acompañan sus pasos con cantares evocadores hacia el sol y la frescura de la lluvia recuerda sus antepasados. Y bajo el éxtasis que produce el encuentro con la tierra nativa, la poeta va tejiendo en el telar del espacio infinito el rostro mapuche.

El lugar es entonces el centro donde se construye la relación con el ecosistema y lo ancestral, que en el fondo son las raíces que componen los territorios como elementos vivos. Desde el punto de vista propuesto por Buell (2005), los lugares son espacios construidos desde la unidad con la sociedad, representando el lugar como una construcción humana, en el que los problemas ambientales afectan profundamente al lugar como tradición:

But modern history has also reversed this process. Whereas for "early human societies" it might be said that "place and society are fused as a unity," with the advent of societies based on economic exchange "the conceptual fusion of space and society is broken" making it difficult, if not impossible, for traditional forms of emplacement. (Comillas de Smith, 1984, citado en Buell, 2005, p.64)

Siguiendo lo anterior es posible pensar en el rescate del territorio, en la medida en que se recupere la relación entre naturaleza y cultura, cuyo vínculo se ha visto afectado por los efectos destructivos de la modernidad capitalista. Entonces, concebir el lugar como un espacio vacío o como materia inmóvil, es caer en la trampa homogeneizadora de Occidente, por lo que, se hace urgente volver a habitar y a (re) mapear estos lugares reconociendo la importancia de la naturaleza como materia viva capaz de cimentar las tradiciones culturales. La poesía como propuesta decolonial que postulamos en esta investigación, logra reformular las relaciones entre el yo y su 
El lugar de la naturaleza en el espacio poético: identidad, pertenencia y experiencia

Julieth Niño

entorno desarticulando el antropocentrismo eurocéntrico dando paso al ecologismo donde la naturaleza es situada como un nuevo territorio que brinda la recuperación cultural de los lugares, restableciendo las conexiones con la tradición y reconstruyendo los imaginarios geográficos.

En este ámbito el territorio está claramente vinculado con la construcción del ecosistema y su relación con los modelos culturales que allí surgen. La naturaleza ha sido desde el comienzo de la historia de la humanidad un símbolo mitológico y religioso cargado de un alto valor cultural. Como lo muestra Eliade (1981):

La naturaleza sigue presentando un encanto, un misterio, una majestad en los que se pueden descifrar vestigios de antiguos valores culturales. No hay hombre moderno cualquiera que sea el grado de su irreligiosidad, que sea insensible a los encantos de la naturaleza. No se trata únicamente de los valores estéticos, deportivos e higiénicos otorgados a la naturaleza, sino también de un sentimiento confuso y difícil de definir en el cual se reconoce todavía la reminiscencia de una experiencia religiosa sagrada. (p. 93)

Las variadas creencias que comparten los pueblos originarios en América Latina en torno a la naturaleza han marcado la historia del continente. La Nuke mapu, por ejemplo, sigue siendo la tierra protectora para las comunidades y también para muchas personas no pertenecientes a las etnias indígenas, quienes han visto en la naturaleza una visión religiosa. Para acercarnos un poco más a la historia mitológica que guarda la naturaleza en los pueblos originarios, tomemos como ejemplo la concepción del cosmos del pueblo mapuche al sur de Chile. Tomando el estudio que nos presenta Grebe, Pacheco y Segura (1972), en la Figura 2, el universo mapuche está orientado en cuatro puntos cardinales donde el Norte se convierte en el punto Este, lugar donde nace la cordillera de los Andes. Cada punto de dicha división está asociado a un orden jerárquico guiado respectivamente por la posición del bien y del mal. Esta organización se piensa bajo la horizontalidad del espacio que permite la división del mundo en cuatro partes.

La posición del cosmos es para lo mapuche una especie de pitonisa que revela el destino que se aproxima. Cuando la tierra se coloca en el lado Este y Sur se anuncian buenas cosechas, pero cuando su rotación gira hacia el punto Oeste y Norte, los infortunios aparecen dejando daños en la tierra y hasta la muerte en la población. Muchas de las visiones mitológicas de los pueblos originarios, se basan en la observación de la naturaleza a la que toman como elemento sagrado, porque no solo produce los alimentos, sino que es también el manto protector que guía y protege a todos los habitantes del territorio. Observemos a continuación la concepción horizontal del cosmos según el pueblo mapuche en la Figura 2. 
El lugar de la naturaleza en el espacio poético: identidad, pertenencia y experiencia

Julieth Niño

Figura 2: Concepción horizontal del Cosmos (Grebe, Pacheco y Segura, 1972, p. 52)
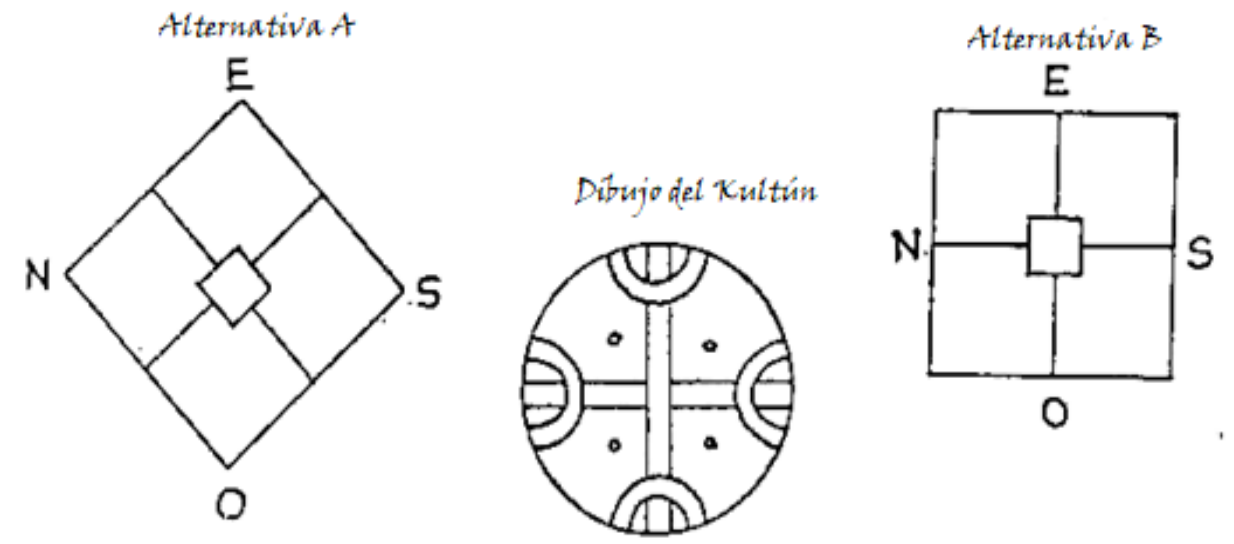

En este sentido, la complejidad mitológica y cultural que guarda la naturaleza ha permitido analizar los estragos que causa la industrialización moderna a nuestro ecosistema y en la cosmovisión de los pueblos originarios. Con la llegada del homo technicus como lo llama Cruz (2014), la naturaleza se posiciona en un lugar de riesgo a causa de las grandes transformaciones que abre la época de la modernidad ${ }^{5}$. Pues cada día la industria ofrece nuevos inventos que nos liberan de los esfuerzos físicos que antes nos robaban parte de nuestro tiempo y energía. La técnica ha llevado a la humanidad hacia una zona de confort, hacia la conquista de la utilidad y la comodidad; en pocas palabras, la técnica ha convertido el mundo del ser humano en un paraíso de facilidades.

Si bien es cierto, al principio, estas manifestaciones despertaron optimismo y entusiasmo, con el pasar del tiempo empezó a emerger una corriente contraria de desaliento y pesimismo, que reclamó la necesidad de un giro decolonial. La causa de semejante cambio de actitud se debe a una serie de hechos que todos conocemos y que no podemos ignorar como son:

- El deterioro de la tierra, la erosión del suelo, ríos sin peces, playas contaminadas, los océanos cubiertos por toneladas de plástico y el extractivismo minero y agrario.

- La fumigación de territorios como estrategia para la erradicación de cultivos de coca, lo cual lejos de controlar la expansión de los cultivos ilícitos, acaba con la siembra para la población local. Además de la cotidianidad del smog y el contagio de enfermedades virales.

- La militarización de los territorios como respuesta a la presencia de grupos armados y las constantes amenazas y asesinatos de líderes y activistas sociales, que generan afectaciones no solo a la vida humana sino también al ecosistema ${ }^{6}$.

\footnotetext{
${ }^{5}$ Considerando la opinión de Cruz (2014), qué afirma que a finales del siglo XIX culmina la época Moderna y se inicia la época de la Técnica que se extiende hasta nuestros días.

${ }^{6}$ Para un acercamiento exhaustivo de los problemas ambientales, consultar: Maya, A. (1993). La trama de la vida las bases ecológicas del pensamiento ambiental. Bogotá: Universidad Nacional de Colombia.
} 
El lugar de la naturaleza en el espacio poético: identidad, pertenencia y experiencia

Julieth Niño

En estas condiciones, la naturaleza que antaño florecía en selvas y valles junto con las aves, todas ellas cargadas de hermosos colores que iluminaban con su canto costas y montañas y los ríos de aguas claras que bañaban los cuerpos desnudos de nuestros ancestros han ido desapareciendo, quedando un conflicto de por medio: el deterioro del ecosistema para ganar dinero y la lucha por conservar el medioambiente para la sobrevivencia.

Varias preguntas surgen a partir de lo anterior: ¿quién habla del lugar de la naturaleza?, ¿quién lo defiende?, ¿es posible volver a habitar los territorios despojados mientras nos encontramos enjaulados en la civilización capitalista y tecnológica? En resumen ¿lograremos un reencantamiento del mundo desde una dimensión poética? La profesora Patricia Noguera (2004) considera que para alcanzar una poetización del mundo, se deben silenciar primero todos los discursos sofocantes de las grandes teorías científicas, políticas, totalitaristas, para dejar que la voz poética se despliegue y pueda ser escuchada. Un reencantamiento del mundo significa volver a habitar los lugares que nos rodean.

En este sentido, la poesía se convierte en la voz de la naturaleza, capaz de integrarse a la infinitud de su grandeza, pero también de denunciar, defender y confrontar los sistemas capitalistas que por décadas han lastimado profundamente la existencia humana. No podemos negar que la tierra ha desaparecido en su materialidad física, pero la semilla del recuerdo sigue creciendo y se mantiene imparable en el resonar del verso. Leamos el poema titulado "NGILLATUN EN LA COSTA", título que hace referencia a una de las ceremonias principales del pueblo mapuche realizadas históricamente a las orillas del mar.

Para poner tranca a la miseria

Cada cierto tiempo

Los Williches de la costa

Desclavan de sus ruka las penas.

Se descuelgan de la historia

Y a Pukatriwe llegan

Espantando con el Ngillatun

al maligno espíritu del hambre

que va en estampida por la cordillera.

Los Williches y el mar

En vigilia

Comulgan tiempos de miseria. (Huinao, 2009, p. 35)

A lo largo del poema hallamos tensiones duales entre la vida terrestre y sobrenatural. Los rituales en la Pukatriwe son celebrados para ahuyentar los espíritus malignos y conocer el futuro, estas dualidades buscan unirse en el acto mismo de lo ceremonial. Siguiendo a Grebe, Pacheco y Segura (1972), en la Figura 3, las ceremonias mapuches están guiadas por la circularidad espacial con que conciben el universo. Dicho movimiento está marcado por la rotación contraria a las manecillas del reloj, en el que el punto cardinal "Este" es el punto inicial del movimiento. Los procesos ceremoniales son de gran valor para la cultura indígena del sur del país. En el poema,

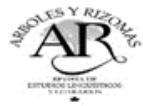


El lugar de la naturaleza en el espacio poético: identidad, pertenencia y experiencia

Julieth Niño

"Los williches de la costa/ desclavan de sus ruka las penas/ para llegar al templo liberados de toda maldad y tristeza" (Huinao, 2009, p. 35). Este templo es la Pukatriwe donde las dualidades entre el bien y el mal desaparecen en la circularidad misma del espacio y los/las herederas de esta tradición religiosa logran purificar y calmar las penas que acechan sus almas y la de toda su comunidad. Este ritual es uno de los más celebrados por el pueblo Williche, se realiza en los meses de primavera debido a la posición geográfica del sol.

Figura 3: Ruka Mapuche (Grebe, Pacheco y Segura, 1972, p. 56)

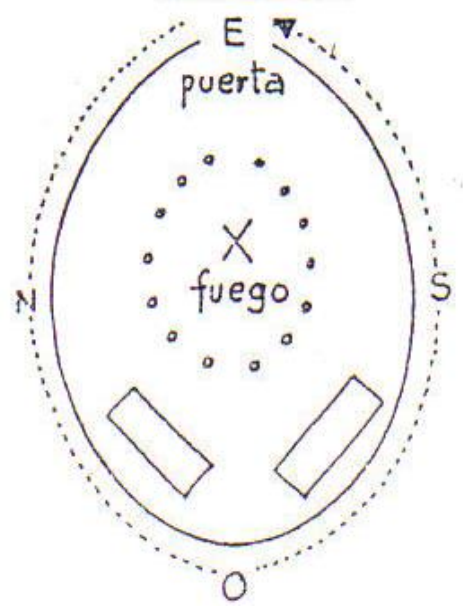

La dimensión territorial interviene en este deseo de arraigo donde se inicia una nueva localización de la cultura mapuche a través del rescate ancestral y místico sobre la naturaleza; es así que la Pukatriwe ha significado para esta comunidad el espacio infinito del universo, la circularidad perfecta. En este sentido, la poesía se posiciona en un escenario social y político que personifica el lugar de la naturaleza rescatando el vínculo cultura/medioambiente, cuerpo/mente, territorio/práctica, lo que resulta central para afirmar la participación de la poesía en los procesos decoloniales. Como lo afirma Escobar (2000):

Los eruditos y activistas de estudios ambientales no solo están siendo confrontados por los movimientos sociales que mantienen una fuerte referencia al lugar, verdaderos movimientos de apego ecológico y cultural a lugares y territorios- sino que también confrontan la creciente comprensión de que cualquier salida alterna debe tomar en cuenta los modelos de la naturaleza basados en el lugar, así como las prácticas y racionalidad culturales, ecológicas y económicas que las acompañan. (p.68)

Los debates que surgen dentro del pensamiento ambiental son indispensables para explorar el complejo entramado de relaciones que se cruzan entre el ser humano y el ecosistema. Esta analogía sugiere ser analizada desde valores éticos y estéticos. En este sentido, la propuesta de Guattari en su ensayo "Las tres ecologías" (1996), resulta pertinente para (re)pensar las formas en que el ser humano convive con el entorno natural. El término ecosofía que propone el filósofo 
El lugar de la naturaleza en el espacio poético: identidad, pertenencia y experiencia

Julieth Niño

francés nos aproxima hacia los problemas ambientales desde un sentido ético-político donde se coloca en cuestionamiento el papel que ha cumplido la historia de la humanidad en el daño ambiental. Entendemos las tres ecologías como el estudio que trabaja los problemas ecológicos desde tres categorías: el medio ambiente, las relaciones sociales y la subjetividad humana.

Este nuevo paradigma formula nuevas prácticas para mitigar el daño ambiental que nos permite plantear una vuelta de tuerca a los valores éticos y culturales para recuperar la relación perdida con la naturaleza. En esta dirección cabe resaltar la conferencia Mundial sobre el Medio Ambiente y el Desarrollo que organizó la Asamblea General de las Naciones Unidas en Julio del 1992, cuya sede principal se instaló en Río de Janeiro, Brasil. Contó con la participación oficial de 153 países y 118 jefes de gobierno ${ }^{7}$. El encuentro resultó histórico porque se plantearon soluciones de tipo cultural y social para frenar la crisis ambiental dejando de lado las fórmulas económicas y tecnologías que hasta el momento daban respuesta a la crisis ecológica. Como lo señaló Maya (1992):

La conferencia de Río se centró en la concepción de que la crisis ambiental no se logra solucionar con recetas económicas o tecnológicas. La cultura como totalidad enfrenta un reto de cambio. A lo largo de la historia el hombre ha tenido que enfrentar en muchas ocasiones cambios drásticos no solo tecnológicos sino también culturales, y la crisis ambiental no es una excepción. Quizá más que nunca en la historia, la sociedad contemporánea se ve abocada a transformaciones radicales si quiere evitar el aniquilamiento de los sistemas vivos. (p. 43)

Las conclusiones del encuentro de Río 92 hicieron hincapié en la necesidad de hacer un llamado a todas las sociedades del mundo para detener el incremento de la contaminación ambiental del planeta Tierra; sin embargo, los aportes hacia la cultura que se trazaron para la agenda XXI por parte de los países ricos ha sido toda una vergüenza (Leff,1995). Desde la experiencia latinoamericana, como lo hemos visto, los problemas ambientales han dejado profundas reflexiones. En el artículo de Eduardo Galeano titulado "No es suicidio, es genocidio y ecocidio" (2005), el autor presenta un espantoso retrato de la degradación ecológica de Latinoamérica, donde culpa no solo a los países industrializados, sino también a todas las naciones locales y nacionales que venden la tierra para su explotación. Es así que lo que pasa en América Latina, solo tiene un nombre y es extractivismo.

Bajo esta perspectiva, la naturaleza se desangra en las manos del poder monetario y sus gritos de dolor reflejan lo complejo que resulta la vida para el ser humano; entonces, la comida sana, el agua limpia, el aire puro y el silencio dejan de ser derechos fundamentales para la vida de las personas y se convierten en privilegios de quienes pueden pagarlo. Es así como la poderosa imagen del Primer Mundo ha logrado legitimar la explotación del suelo en el territorio

\footnotetext{
${ }^{7}$ Cabe recordar, según lo relata Binns (2004), que cuando el presidente de los Estado Unidos George Bush (padre) subió al avión presidencial que lo llevaría a la conferencia de Río, anunció: "nuestro modo de vida no puede ser objeto de negociaciones" ( p. 13)
} 
El lugar de la naturaleza en el espacio poético: identidad, pertenencia y experiencia

Julieth Niño

latinoamericano para implantar como larvas el crecimiento del capitalismo; respecto a esto Galeano (2005) afirma que: "si los siete millones de pobladores que habitan el planeta consumieran lo mismo que los países desarrollados de Occidente, haría falta diez planetas como el nuestro para satisfacer todas sus necesidades" (p. 3). Aun así, los gobiernos del Sur siguen alimentando día a día la tiránica conquista de la globalización ${ }^{8}$.

Podemos pensar que la rapidez con la que se ha propagado el poder económico se debe principalmente al ocultamiento de la crisis ambiental; la silenciosa muerte que por años ha sufrido nuestro planeta Tierra ha generado una serie de problemas que poco a poco han ido apareciendo. La época de la técnica ha lanzado una lucha a muerte contra la naturaleza en la que la vida del ser humano se pone en peligro. Cruz (2004) nos dice al respecto: "el hombre ha perdido el control de las fuerzas que desencadenó, de que como en la leyenda del aprendiz de brujo comienza a ser dominado por su propia creación, y que corre el peligro en convertirse en su víctima” (p. 305).

La enorme amenaza de supervivencia, producto de la industrialización, ha llevado a la humanidad a (re)construir caminos que le ayuden a sembrar nuevamente las raíces en la tierra. Se trata de volver a la armonía con la naturaleza, de volver habitar la esperanza de construir un lugar donde posar su existencia. Todo esto ha significado una búsqueda cultural contra hegemónica que despierta un tipo de conciencia histórica.

La importancia de la cultura será adecuada para analizar las identidades que van surgiendo a través del tiempo, los procesos históricos logran recuperar en la infinitud del universo los recuerdos que han constituido la existencia del ser humano, para llevarlos luego hacia una conciencia objetiva y desde esa objetividad dar explicación a una realidad vivida. El historiador y filósofo Jörn Rüsen asegura que la historia influye en las prácticas o experiencias de la vida humana:

La conciencia histórica ha podido ser descrita como una realidad elemental y general de la explicación humana del mundo y de sí mismo, y así ha sido elevada a la categoría de un tema de investigación propio, de significado incuestionablemente práctico de la vida. Si se examina el papel que juega la conciencia histórica en la vida de la sociedad, aparece como una contribución cultural fundamentalmente específica, que afecta e influye en casi todas las áreas prácticas de la vida humana. (citado en Castaño, 2011, p. 231)

El concepto de cultura implica analizar la existencia humana desde una dimensión empírica, donde la experiencia resulta ser la única respuesta para estudiar y solucionar los problemas ambientales. Es innegable que la época de la técnica manipuló la conciencia de las personas con una serie de privilegios y comodidades que fueron silenciando los problemas que

\footnotetext{
${ }^{8}$ Galeano (2005) utiliza el término "Tercer mundo" para hacer referencia a las naciones no industrializadas como son las regiones en Latinoamérica y África principalmente. Dicho término tiene su origen en el periodo de la Guerra Fría y hace alusión a todos los países no pertenecientes a los dos bandos en conflicto. Cabe resaltar que esta expresión ha sido criticada y rechazada en la actualidad; en nuestro caso, la hemos tomado para mostrar lo irónico que resulta pensar en Primer y Tercer Mundo.
} 
El lugar de la naturaleza en el espacio poético: identidad, pertenencia y experiencia

Julieth Niño

causaba la industrialización al ecosistema. Es así que el rescate de la cultura histórica dentro del pensamiento moderno ayuda a abrir nuevas formas de entendimiento donde la relación entre el humano y el mundo son interpretadas como discursos del pasado. En este sentido, la realidad se transforma en un mediador que busca en la historia la construcción de identidades, aquellas que han sido mutiladas por la racionalidad unidireccional de la civilización. Los poetas modernos han hecho un enorme trabajo por volver a vincular las identidades latinoamericanas extraviadas por los procesos de globalización. Observemos el siguiente poema titulado "Walinto" de G. Huinao (2009).

Un niño tiene que haber pintado

las pampas de Walinto.

Por la forma de sus árboles

lo simple de su geografía.

Sus rukas porfiadas al tiempo

se levantan en resistencia día a día.

Allí engendraron mis ancestros

Para que la historia continúe. (p. 62)

Walinto pertenece a la zona central del sur de Chile, se encuentra ubicado exactamente en la región de los Lagos, en el kilómetro 6 de Riachuelo al sur de Osorno, es uno de los asentamientos indígenas de origen Mapuche que se mantiene aún a pesar del tiempo. Esta poesía nos acerca como lectores hacia un espacio trascendental donde la vida y la muerte dialogan en un mismo plano.

En la primera estrofa, la simpleza del lugar se dibuja en la inocencia de las formas y las palabras con que describe el hablante lírico el territorio. Logramos imaginar una llanura con figuras rectas y asimétricas que la constituye una serie de colores vivos que van entre los verdes intensos y algunos rojizos que se posan como rayos de sol y se extienden a su vez en la planicie de las pampas. Este juego de formas, colores, percepciones y sensaciones se va dimensionando a través de la mirada infantil de un niño que pinta la geografía de Walinto.

En la siguiente estrofa, su descripción se profundiza mostrando ciertos aspectos del lugar que son asociados, a primera vista, con una permanencia histórica, un volver al lugar. El uso de palabras en mapudungun como Ruka o Walinto acerca al lector/a a habitar nuevas territorialidades; en este punto nos podemos preguntar ¿qué tipo de historia es la que narra el sujeto poético?, a lo que respondemos que es una historia biográfica, testimonial, es una poesía que conecta con la realidad, trazada por acontecimientos que van desde la enunciación de un lugar propio como Walinto hasta la descripción gráfica del territorio. Las palabras escritas en lengua originaria que sobresalen en el texto permiten vincular la tradición mapuche de la oralidad con el acto de escribir. En este punto coincidimos parcialmente con la interpretación de Moraga (2001), quien describe la poesía de Graciela Huinao como "una escritura que devela la memoria de una historia olvidada" (p. 23).

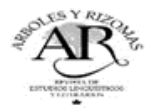


El lugar de la naturaleza en el espacio poético: identidad, pertenencia y experiencia

Julieth Niño

La literatura trabaja, entonces, como un dispositivo social que logra la identificación colectiva dentro de una comunidad. Siguiendo a Halbwachs (1968), "el único medio para salvar los recuerdos es fijarlos por escrito en una narrativa ordenada ya que, si las palabras y los pensamientos mueren, los escritos permanecen” (p. 210). De aquí la necesidad de trascribir la oralidad de la historia y además de dibujar los territorios que aparentemente se encuentran desaparecidos, como es el caso de Walinto.

Para las comunidades precolombinas de América Latina, la recuperación de la identidad se convierte en un instrumento clave para su existencia. En este proceso, la literatura encara los espacios colonizados y en la medida que el hablante lírico se acerca a estos lugares del recuerdo; su anhelo por lo perdido lo impulsa a escribir aquello que ha olvidado. Para la profesora Navarrete (2018), la poesía mapuche tiene el poder de enlazar al lector/a con el territorial, observemos:

Dadas las largas historias de desplazamiento, las nociones de identidad y territorio se han visto por siempre alteradas, por lo que la poesía presenta un acceso importante para reivindicar las múltiples maneras del mundo Mapuche (...) La voz lírica también afirma un nuevo territorio y demanda del huinca una respuesta que posibilite el reconocimiento de su lugar en un espacio vital donde se encuentran todos los ancestros. (p. 30).

La memoria narrativa es capaz de vivir en la conciencia colectiva desde la palabra escrita, su resonar se instala en la sonoridad del tiempo para dar paso al encuentro temporal entre pasado, presente y futuro. De esta forma, la dimensión estética de la poesía rescata la sensibilidad perdida que por años ha extraviado la sociedad moderna; los lugares vuelven a inscribirse como elementos vivos y la memoria se convierte en el único medio para salvar las identidades que han quedado abandonadas en la eternidad del tiempo.

Los problemas ambientales nos obligan a reflexionar acerca del lugar que ocupa el ser humano en la naturaleza, nos invita a regresar por los oscuros caminos de lucha y resistencia que antaño vivieron los hombres y mujeres que habitaron este planeta. La identidad que se ha creado en el pensamiento latinoamericano no puede seguir siendo formulada en términos meramente ontológicos, sin considerar su carácter empírico. Para Quijano (1988), América Latina debe ser entendida como un suceso infinito de nuevos acontecimientos históricos (empíricos) que desembocan en una racionalidad liberadora.

Los movimientos ecológicos que se han organizado en los últimos tiempos tienen como respuesta la defensa del lugar como territorio cultural. La principal causa de conflicto entre sociedad y Estado se debe a la desterritorialización que han causado las industrias extractivistas en el territorio Latinoamericano. Resulta adecuado pensar que el activismo ambiental presenta una clara relación entre lugar, cultura y naturaleza; donde las diversas subjetividades se instalan en un espacio en común para denunciar la pérdida del territorio. En este sentido, la poesía está comprometida con la tarea ecológica, pues el artista contemporáneo debe ser un pensador social, un activista cultural, un embajador independiente y por encima de todo, un gran comunicador 
El lugar de la naturaleza en el espacio poético: identidad, pertenencia y experiencia

Julieth Niño

involucrado en los grandes debates de la época (Bourriad, 2009). Es así que estudiar la figura del sujeto poético como un actor social en los problemas ambientales, será ideal para posicionar la escritura lírica dentro del proyecto descolonizador que se ha desarrollado en el pensamiento latinoamericano de los últimos tiempos.

\section{Conclusión}

Como lo señalamos al inicio de la investigación, la poesía funciona como un elemento estético que denuncia los problemas ambientales, pero también como un dispositivo de la memoria que desvela una acción práctica a través del testimonio y la denuncia. Es posible establecer, por lo tanto, en estas escrituras un intento por volver a habitar los lugares en un diálogo viviente entre el pasado, el presente y el futuro; pues solo a través de estos cruces temporales somos capaces como lectores de transitar por los territorios despojados.

Estas poéticas abren nuevos caminos para pensar en relación a la naturaleza, a lo político, a lo social, a la idea de experiencia, y a la propia filosofía de la vida. Van desterrando historias olvidadas por el paso del tiempo, que nos plantean preguntas que nos llevan hacia profundas reflexiones cargadas de múltiples afectos que interpelan nuestros modos de estar en el mundo. Estas escrituras desprenden debates fundamentales inscritos a partir de varios discursos como el discurso de la memoria, el discurso testimonial y los discursos ambientales que resultan fundamentales para la (re)construcción de los lugares y del sujeto mismo, pues como lo postula Le Breton (2002) los seres humanos no habitamos el mundo sin modificarlo.

La naturaleza ha sido desde comienzos de la historia de la colonización un objeto de conquista. El bosque constituyó una amenaza para los invasores, pues allí se depositaban los valores culturales y religiosos que daban significado a la existencia social de las comunidades. De aquí la importancia de realizar un estudio acerca de la idea de lugar o territorio, pues esto resulta clave para entender las relaciones que se establecen dentro de los mismos textos. La urgencia por recuperar el ecosistema y abolir las estructuras colonizadoras ha logrado que la crítica literaria se integre en los procesos decolonizadores, postulando críticas que agrieten los sistemas oficialistas de la nación y permitan abrir "otros" espacios de reflexión y de acción donde la poesía, principalmente, se posiciona en un campo de acción (praxis) dentro de estos movimientos de carácter ambiental.

El estudio de la poesía mapuche nos coloca en un lugar determinado que permite dar una dirección al estudio investigativo donde el lugar se encuentra situado en un solo espacio, el sur de Chile. Es así que los ejercicios cartográficos que se presentan durante el desarrollo del texto nos ayudan como lectores a acércanos, por un lado, a la cosmovisión mapuche, y por el otro, a la denuncia de los problemas ambientales. La poesía ancestral funciona en esta investigación como un mecanismo de representación donde las experiencias personales logran resolver la escisión ser humano/naturaleza y volver a la unidad perdida entre el cuerpo, la tierra, la historia y la pertenencia étnica.

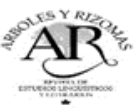


El lugar de la naturaleza en el espacio poético: identidad, pertenencia y experiencia

Julieth Niño

\section{Referencias}

Binns, N. (2004). ¿Callejón sin salida? La crisis ecológica en la poesía hispanoamericana. Zaragoza: Prensa Universitarias de Zaragoza.

Bourriad, N. (2009). Radicante. Buenos Aires: Adriana Hidalgo editora S.A.

Buell, L. (2005). The future of Enviromental Criticism: Enviromental Crisis and Literary Imagination. New York: Blackwell Publishing.

Castaño, L. (2011). Jörn Rüsen y la conciencia histórica. Revista Historia y Sociedad, 23 (21), 223-245. http://www.scielo.org.co/pdf/hiso/n21/n21a10.pdf

Cruz, D. (2014). Tabula Rasa. Bogotá: Universidad Nacional de Colombia.

Escobar, A. (2000). El lugar de la naturaleza y la naturaleza del lugar: ¿globalización o postdesarrollo?. Santafé de Bogotá: Cerec.

Eliade, M. (1981). Lo Sagrado y lo Profano. Madrid: Punto Omega.

Galeano, E. (2005). No es un suicidio, es un genocidio y ecocidio. Buenos Aires: OSAL.

Grebe M., Pacheco, L. y Segura, J. (1972). Cosmovisión Mapuche. Cuadernos de la Realidad Nacional, (14), 46-73.

http://www.artificios.uchile.cl/content/docs/Cosmovision_mapuche.pdf

Guattari, F. (1996). Las tres ecologías. Madrid: Pretextos.

Hall, S. (1996). Cuestiones de identidad cultural. Mendoza: Amorrortu editores S.A.

Halbwachs, M. (1968). Memoria colectiva y Memoria histórica. Zaragoza: Prensas Universitarias de Zaragoza.

Huinao, G. (2009). Wallinto. Santiago de Chile: Cuarto propio.

Lara, M. (2006). Hilando la Memoria de siete poetas Mapuche. Santiago de Chile: Cuarto Propio.

Leff, E. (1995). ¿De quién es la naturaleza? Sobre la reapropiación social de los recursos naturales. Gaceta Ecológica, (37), 28-35. https://nuso.org/articulo/la-reapropiacion-social-de-lanaturaleza-y-la-construccion-local-de-la-racionalidad-ambiental/

Le Breton, D. (2002). Antropología del cuerpo y modernidad. Buenos Aires: Nueva visión.

Marimán, P. (2018). Encuentro cumbre de redes territoriales "Wallmapu Patagonia". Mapuexpress.https://www.mapuexpress.org/2018/05/23/encuentro-cumbre-de-redesterritoriales-/

Maya, A. (1992). Conferencia Mundial Sobre Medio Ambiente y Desarrollo. Bogotá: Instituto de Estudios Ambientales Universidad Nacional de Colombia.

Maya, A. (1993). La trama de la vida: las bases ecológicas del pensamiento ambiental. Bogotá: Universidad Nacional de Colombia

Mignolo, W. (2007). La idea de América Latina. Barcelona: Editorial Gedisa, S.A.

Mora, M. (2013). Poesía mapuche: la instalación de una misma étnica en la literatura chilena. Una revista de historia social y literatura de América Latina 10 (3), 21-53.

https://acontracorriente.chass.ncsu.edu/index.php/acontracorriente/article/view/699/1170

Morales, P. (2002). Sigo creyendo que somos polvo de estrellas. Santiago de Chile: Intramuros.

Moraga, F. (2001). Entre memorias y Re-escritura de la historia: Esbozo de una aproximación a la poesía escrita mapuche en Graciela Huinao y Adriana Pinda. Revista Literatura y Lingüística, (13), 25-55. https://scielo.conicyt.cl/scielo.php?script=sci arttext\&pid=S0716-58112001001300003 
Navarrete, C. (2018). Territorio y experiencia: La experiencia del desplazamiento en la poesía de mujeres Mapuche. Revista de Letras, São Paulo,58 (2), 29-42.

https://www.jstor.org/stable/26757478

Noguera, P. (2004). El reencantamiento del mundo. Manizales: Editorial Universidad Nacional de Colombia.

Offen, K. (2009). O mapeas o te mapean: Mapeo indígena y negro en América Latina. Revista Tabula Rasa, (10), 163-189. http://www.scielo.org.co/pdf/tara/n10/n10a06.pdf

Quijano, A. (1988). Modernidad, Identidad y Utopía en América Latina. Lima: Sociedad y Política, ediciones.

Sarmiento, D. (1845). Civilización y Barbarie. Buenos Aires: Biblioteca del Congreso Nacional. Zambrano, G. (2008). Cartografías Literarias. Mérida: Universidad y Pensamiento 